\title{
Fungal air contamination in distinct sites within a municipal landfill area
}

\author{
K. Frączek ${ }^{1}$ J. Kozdrój $j^{1,2}$ (1) R. L. Górny ${ }^{3}$ - M. Cyprowski ${ }^{3}$ M. Gołofit-Szymczak ${ }^{3}$
}

Received: 19 September 2016/Revised: 18 February 2017/Accepted: 27 April 2017/Published online: 15 May 2017

(C) The Author(s) 2017. This article is an open access publication

\begin{abstract}
Municipal wastes collected in landfills are a significant source of air contamination and frequently characterize by elevated concentrations of different fungi. Posing a serious health threat to landfill workers and local residents, the fungal aerosol has to be monitored with respect to its quantity and quality. In this study, concentrations of airborne fungi, their particle size distribution, species composition and the presence of cytotoxic strains of Aspergillus fumigatus were assessed in different sites within the landfill area. The quantitative and qualitative changes in the fungal aerosol were determined with respect to a season and landfill activity level (i.e. exploitation or standstill periods). Within the landfill area, particular sites were grouped with regard to airborne fungi concentrations and similarities in species composition. The qualitative analysis indicated that 43 species were shared during both sampling times, and only nine species were characteristic for the standstill period. Among fungal isolates, 21 strains
\end{abstract}

Responsibility editor: Xu Han.

J. Kozdrój

j.kozdroj@ur.krakow.pl

1 Department of Microbiology, University of Agriculture in Krakow, Mickiewicza 24/28, 30-059 Kraków, Poland

2 Institute of Experimental Biology, Kazimierz Wielki University, Powstańców Wielkopolskich 10, 85-090 Bydgoszcz, Poland

3 Department of Chemical, Aerosol and Biological Hazards, Central Institute for Labour Protection, National Research Institute, Czerniakowska 16, 00-701 Warsaw, Poland of A. fumigatus revealed cytotoxic activity expressed at different levels, depending on the fungal extract concentrations used in the MTT assay. The results suggested that exposure (especially in summer) to small airborne particles, containing distinct species, may occur not only in the active sector but also in close vicinity to the landfill. Hence, microbial monitoring of the landfill and surrounding area should be carried out taking into account both quantitative aspect supplemented by size distribution analysis and qualitative features, especially of those strains possessing cytotoxic activity.

Keywords Bioaerosol · Cytotoxic fungi - Landfill surroundings $\cdot$ Municipal waste $\cdot$ Species composition

\section{Introduction}

Municipal landfills containing many different wastes with high contribution of organic substrates form specific habitat suitable for the growth of very diverse spectrum of microorganisms. Among them, saprophytic fungi as decomposers of organics constitute a major group. In consequence, after release into the air, these micro-organisms comprise a distinct part of bioaerosol that may disperse within the landfill and surrounding areas (Frączek and Ropek 2011). Being airborne, fungi become significant environmental contaminants, which concentration and species composition changes depending on atmospheric conditions, the landfill localization and its exploitation. In addition, the bioaerosol characteristics are closely related to season and even changes on a daily basis (Kaarakainen et al. 2008).

In the landfill, large quantity of collected wastes is the source of dust particles that, as a mean of transport, may additionally increase fungal contents in the air. Each 
activity that is associated with waste delivery, planting with mechanical equipment, compacting and covering increases the dustiness and by that bioaerosol concentration, especially within the area of the landfill active sector. The microbial particles may be quickly transferred to long distances; however, their fates in the air depend on their sizes (Clauß 2015). The larger aggregates of microbes and dust $(10-100 \mu \mathrm{m})$ fall down (from a few minutes to a few seconds, respectively) on the ground near their sources of emission. On the other hand, smaller particles $(0.5-10 \mu \mathrm{m})$, being suspended on the air for longer periods of time, are usually transported by air for longer distances. In consequence, the area surrounding the municipal landfill is exposed to the microbial contaminants as well. Among them, the most frequently found in the air are fungal representatives of Cladosporium, Penicillium, Aspergillus, Alternaria, Mucor, Fusarium, Rhizopus and Trichoderma genera (Huang et al. 2002; Kaarakainen et al. 2008; Grisoli et al. 2009; Kalwasińska et al. 2014; Abdel Hameed et al. 2015)

The threat caused by airborne fungi is associated with their increased concentration and biological activity of their particulates and consequently, higher exposure influences first and foremost the landfill workers and local residents. Different fungal diseases, mostly those of respiratory system (e.g. allergic alveolitis and asthma), if reported are a consequence of inhalation of particles smaller than $5 \mu \mathrm{m}$ in diameter that easily penetrates lower respiratory tract (Douwes et al. 2003; Menzies et al. 2011; Denning et al. 2014; Schlosser et al. 2016). The biological threat grows when the bioaerosol community includes some opportunistic or even pathogenic fungal species. These organisms (e.g. Aspergillus fumigatus and A. flavus) proliferate in composting substrates, which are their major source of emission into the air (Fischer et al. 1999; Krikštaponis et al. 2001; Abdel Hameed et al. 2015; Schlosser et al. 2016). Among a relatively broad spectrum of fungal species, an identification of strains that show cytotoxic activity in exposed hosts is of special concern. This cytotoxicity is usually related to mycotoxins produced by pathogenic strains (Hedayati et al. 2007; Gauthier et al. 2012; Sudini et al. 2015). However, the presence of toxic strains, especially in the air of a municipal landfill, has not been yet reported, except contaminated air in biowaste facilities or farming environment (Fischer et al. 1999, 2000; Lanier et al. 2010).

In this study, we have assumed that the fungal aerosol might quantitatively and qualitatively differ in distinct sites within the municipal landfill and surrounding area. The objectives were to assess the impact of activity present within the landfill (i.e. the period of exploitation or standstill) on the airborne fungi concentration, including their distribution according to the size of airborne microbial particles. In addition, this impact was also evaluated with regard to the level of species composition similarity between the studied sampling sites being compared. Furthermore, we aimed to verify the hypothesis that highly cytotoxic strains of A. fumigatus might be isolated from the active sector of the landfill compared to those strains gathered in other sites.

The air samples were collected throughout 2012 followed by laboratory analyses conducted in University of Agriculture in Kraków and Central Institute for Labour Protection-National Research Institute in Warsaw.

\section{Materials and methods}

\section{Air sampling}

Air sampling was performed at the municipal landfill of Barycz that is located within the town area of Kraków (Malopolska region in Poland) bordering to the east of the Wieliczka town $\left(\mathrm{N} 49^{\circ} 58^{\prime} 59.9988^{\prime \prime}\right.$, E $\left.20^{\circ} 1^{\prime} 0.0012^{\prime \prime}\right)$. The landfill (total area of 37 ha) has been exploited since 1974, and it is the best-organized municipal landfill in Poland. Full description of the studied site and details of air sampling have been given in the article of Frạczek and Kozdrój (2016). Briefly, the air samples were collected at 17 sampling points, comprising the active sector (S3), adjacent forest (S4-S9), farmlands (S1, S10, S12, S13, S15-S17) and meadows (S2, S11, S14), located at different distance $(104-1187 \mathrm{~m})$ from the reference location (S3). The bioaerosol for quantitative analyses was sampled monthly throughout 2012 between 9 a.m. and 2 p.m. The identification of fungal species was performed using samples collected twice per month, from June to August. The study strategy assumed to conduct measurements in all sampling sites during the landfill exploitation and standstill in two consecutive days.

\section{Quantitative and qualitative analyses of fungal aerosol}

A six-stage Andersen cascade impactor (model 10-710, Graseby-Andersen, Inc., Atlanta, GA, USA) was placed at a height of 1-1.5 $\mathrm{m}$ above the ground level to simulate aspiration from the human breathing zone. The air was sampled at a flow rate of $28.3 \mathrm{~L} \mathrm{~min}^{-1}$ for a 5-min period, yielding each time a volume of $0.1415 \mathrm{~m}^{-3}$. The fungal particles were collected on malt extract agar (MEA; Merck, Warsaw, Poland). The Petri dishes were placed on all 6 
impactor stages allowing determination of size distribution of airborne particles $(>7,7-4.7,4.7-3.3,3.3-2.1,2.1-1.1$ and $1.1-0.65 \mu \mathrm{m})$. A calibration of the air stream was made each time before and after the sampling using a digital Gillian $^{\circledR}$ Gilibrator-2 flow meter equipped with 2-30 L min ${ }^{-1}$ cell (Sensidyne, Inc., Clearwater, FL, USA). Immediately after sampling, the Petri dishes were transported to the laboratory in metal chambers placed in a mobile refrigerator box to prevent physical damages of the collected biological material. All bioaerosol measurements were conducted in duplicates, and the average concentrations were taken for further calculations.

Each time before sampling, the MEA medium was checked for sterility and quality. For this purpose, the MEA dishes were incubated at 22 and $37{ }^{\circ} \mathrm{C}$ followed by inoculation with reference fungal strains (Penicillium brevicompactum KKP/468, Cladosporium cladosporioides KKP/907, Aspergillus versicolor KKP/446) obtained from the collection of Institute of Agricultural and Food Biotechnology (IAFB, Warsaw, Poland). The reference strains were incubated at $30{ }^{\circ} \mathrm{C}$ in a growth cabinet.

After air sampling, the Petri plates were incubated for four days at $30{ }^{\circ} \mathrm{C}$ followed by additional four days at $22{ }^{\circ} \mathrm{C}$. The concentrations of airborne fungi, as colonyforming units per $\left.1 \mathrm{~m}^{3}(\mathrm{cfu} \mathrm{m})^{-3}\right)$, were calculated separately for each step of the impactor, and globally for six steps. The final cfu values were always corrected according to the manufacturer conversion table that permits to transform the empirical data into the actual values of cfu present in $1 \mathrm{~m}^{-3}$ of the collected air.

For qualitative detection of isolated fungal species, routine macroscopic and microscopic procedures were performed, followed by identification using recommended keys (Fisher and Cook 1998; Samson et al. 2004). The yeast-like fungi were additionally identified using a biochemical API C AUX test (bioMérieux, Marcy L'Etoile, France).

\section{Detection of cytotoxic strains of $A$. fumigatus}

Since A. fumigatus is commonly found in municipal landfills and can be harmful for the landfill workers and local residents, this species was selected for assessment of cytotoxic activity. In total, 21 strains of A. fumigatus isolated from the air samples were chosen to a cytotoxicity MTT test. The MTT assay is a sensitive biochemical tool that allows determining general cytotoxicity of fungi using swine kidney (SK) cells, reactive to the majority of mycotoxins. The assay is based on conversion of yellow tetrazolium salt (3-(4,5-dimethylthiazol-2-yl)2,5-diphenyltetrazolium bromide) by not damaged SK cells into violet formazan insoluble in water. For the cells damaged or destroyed by mycotoxins, the reaction is less intensive or does not occur at all (Hanelt et al. 1994). The SK cells $\left(2.2 \times 10^{5}\right)$ were cultivated in a mixture of ethanoldimethyl sulphoxide-minimum medium with Earle's salts (MEM) supplemented with antibiotics (penicillin and streptomycin; Sigma-Aldrich, Poznań, Poland) and foetal calf serum (Sigma-Aldrich) according to the procedure described by Gniadek et al. (2010). Chloroform spore extracts of the fungal strains were added to the medium forming 1:2 dilution series with the tested concentrations ranged between 31.25 and $0.061 \mathrm{~cm}^{2} \mathrm{~mL}^{-1}$. The MTT reagent $(20 \mu \mathrm{L})$ was then added to each mixture, and the multiwell plates were incubated for $4 \mathrm{~h}$. The absorbance values were spectrophotometrically measured at $510 \mathrm{~nm}$ with an ELISA reader.

All absorption values of the samples were considered toxic when they were below $50 \%$ of the division activity. As a result, depending on the dilution level, the maximum acceptable toxic concentrations were ascertained, namely the smallest tested sample in $\mathrm{cm}^{2} \mathrm{~mL}^{-1}$ that showed toxic effect on the SK cells $\left(\mathrm{IC}_{50}\right)$.

\section{Data analyses}

The one-way analysis of variance (ANOVA) followed by the least significant difference test (LSD) was used to compare the fungal aerosol concentrations between the studied sites. These concentrations were also correlated (Pearson correlations) with temperature and relative humidity $(\mathrm{RH})$ of the air in each sampling seasons. All tested relationships were considered significant at $p \leq 0.05$. A spatial distribution of the bioaerosol within the landfill area was analysed by a sophisticated interpolation engine, transforming cfu data, as irregularly spaced XY points, into graphical maps (Surfer 10, Golden Software, Inc., Golden, CO, USA). A Venn diagram illustrating the similarity of fungal species composition in air samples collected during the exploitation and standstill time of the municipal landfill was generated using Venny 2.1.0 software (http://bioinfogp.cnb.csic.es/tools/venny/index.html). In this way, the species that were specific for a separate sampling season and those found in the air during both landfill activity periods were determined. In addition, to compare the species composition in the corresponding sites of the landfill area, a joining method of the cluster analysis (CA) module and the clustering algorithm of Ward were applied (Statistica 6.0, StatSoft, Kraków, Poland). As a result, dendrograms showing clustering trends among all fungal isolates were generated for the exploited and standstill periods. 


\section{Results and discussion}

\section{Quantitative analysis of fungal aerosol}

Municipal wastes are suitable substrates for growth of different fungi that can release their conidia and mycelium particles into the air. The concentrations of airborne fungi within the landfill area range usually between $10^{3}$ to $10^{4}$ $\mathrm{cfu} \mathrm{m}^{-3}$ (Kaarakainen et al. 2008; Kalwasińska et al. 2014; Abdel Hameed et al. 2015; Schlosser et al. 2016). Although fungal abundance may differ among respective landfill sites and surrounding area, most studies have been typically reporting mean values as representative for the whole landfill area. In this study, the concentrations of fungal aerosol determined at the controlled landfill sites ranged from 112 to $16,445 \mathrm{cfu} \mathrm{m}^{3}$, and they were mostly depended on the season (Fig. 1). The highest concentrations $\left(1,439\right.$ to $\left.16,445 \mathrm{cfu} \mathrm{m}^{-3}\right)$ were noted in summer in the active sector (S3) and within the sites close to the adjacent landfill (11 out of 17 sampling stands). They were significantly higher (LSD test: $p \leq 0.05$ ) than those measured in autumn (172-3567 $\left.\mathrm{cfu} \mathrm{m}^{-3}\right)$, winter $\left(112-2531 \mathrm{cfu} \mathrm{m}^{-3}\right)$ and spring (245-1939 $\left.\mathrm{cfu} \mathrm{m}^{-3}\right)$.

Regarding microbiological contamination of the air, in Poland the old standard PN-89/Z-04111/03 from 1989 defining a degree of atmospheric pollution with fungi is still in force; however, it allows the use of a sedimentation method in quantitative assessment of such bioaerosol. This standard proposes four degrees of outdoor air contamination treating the fungal concentrations below 3000 , between 3000 and 5000, between 5000 and 10,000 and above $10,000 \mathrm{cfu} \mathrm{m}^{-3}$ as clean air, moderately clean

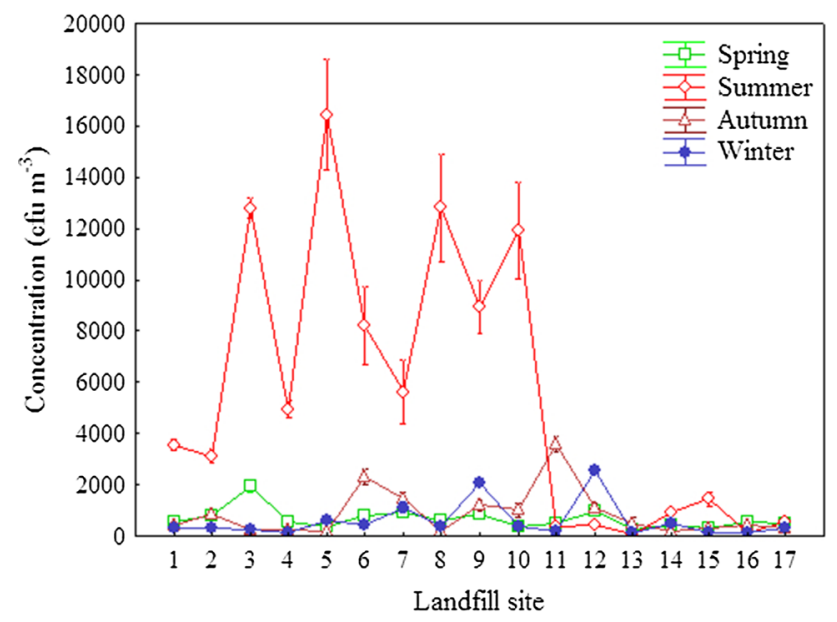

Fig. 1 Seasonal concentrations $\left(\mathrm{cfu} \mathrm{m}^{-3}\right)$ of the fungal aerosol at sampling sites of the studied landfill area. The bars represent standard error values of two repeats air in autumn season, air pollution adversely influencing human natural environment and pollution threatening such environment, respectively. Recently prepared alternation for this standard assumed that the assessment of outdoor air contamination can be performed using both the quantitative and qualitative methods. The quantitative estimation (based on volumetric methods only) posits that the concentration of each bioaerosol compound should not exceed its threshold limit value (TLV) proposed for the air of residential premises, i.e., for the environment, in which majority of the population spend most of its time during a day. In case of fungal aerosol, if its concentration exceeds the TLV of $5000 \mathrm{cfu} \mathrm{m}^{-3}$ such outdoor air should be recognized as "microbiologically polluted" and such conditions as "unacceptable" (Górny et al. 2011). According to that, fungal concentrations in the air at studied municipal landfill sites exceeded the above mentioned TLV in 11 out of 68 cases, reaching the level of pollution considered as threatening for human environment $\left(\geq 10,000 \mathrm{cfu} \mathrm{m}^{-3}\right)$ at four sites (S3, S5, S8 and S10) in summer. The increase in fungal abundance in the air was significantly associated with higher air temperature $(r=0.43, p \leq 0.05)$; however, higher values of air relative humidity $(\mathrm{RH})$ were negatively correlated $(r=-0.39, \quad p \leq 0.05) \quad$ with airborne fungal concentrations.

Seasonal climatic changes condition both growth and survival of microbial propagules in the air, and are strictly connected with microclimatic zones (Fang et al. 2008; Kaarakainen et al. 2008; Abdel Hameed et al. 2015; Schlosser et al. 2016). For example, Huang et al. (2002) found higher concentrations of airborne fungi in winter what was attributed to geographic characteristics of the sampling area located in southern Taiwan. In this location, $\mathrm{RH}$ was reported lower in winter than in summer, which could support higher abundance of fungal particles in the air, probably due to increased emission from their sources as a result of environmental changes (low $\mathrm{RH}$ as a major stressor favouring conidia production by microbial colonies). In temperate climatic zone, higher temperature, lower RH and wind speed, are found in summer. In consequence, airborne transport of fungal propagules is limited to the close vicinity of microbial source and the residents nearby the municipal landfill are more exposed to the bioaerosol in this season (Nielsen et al. 2000). Both described above observations were confirmed in the case of the studied municipal landfill of Barycz and supported by the analysis of particle size distribution of fungal aerosol (see below).

The abundance of micro-organisms in the air is also strictly related to the environmental presence of dust particles. In the case of landfill, all activities such as transport, unloading, levelling and compacting of wastes with 


\section{A}

\section{Exploitation $\left(\mathrm{cfu} \mathrm{m}^{-3}\right)$}

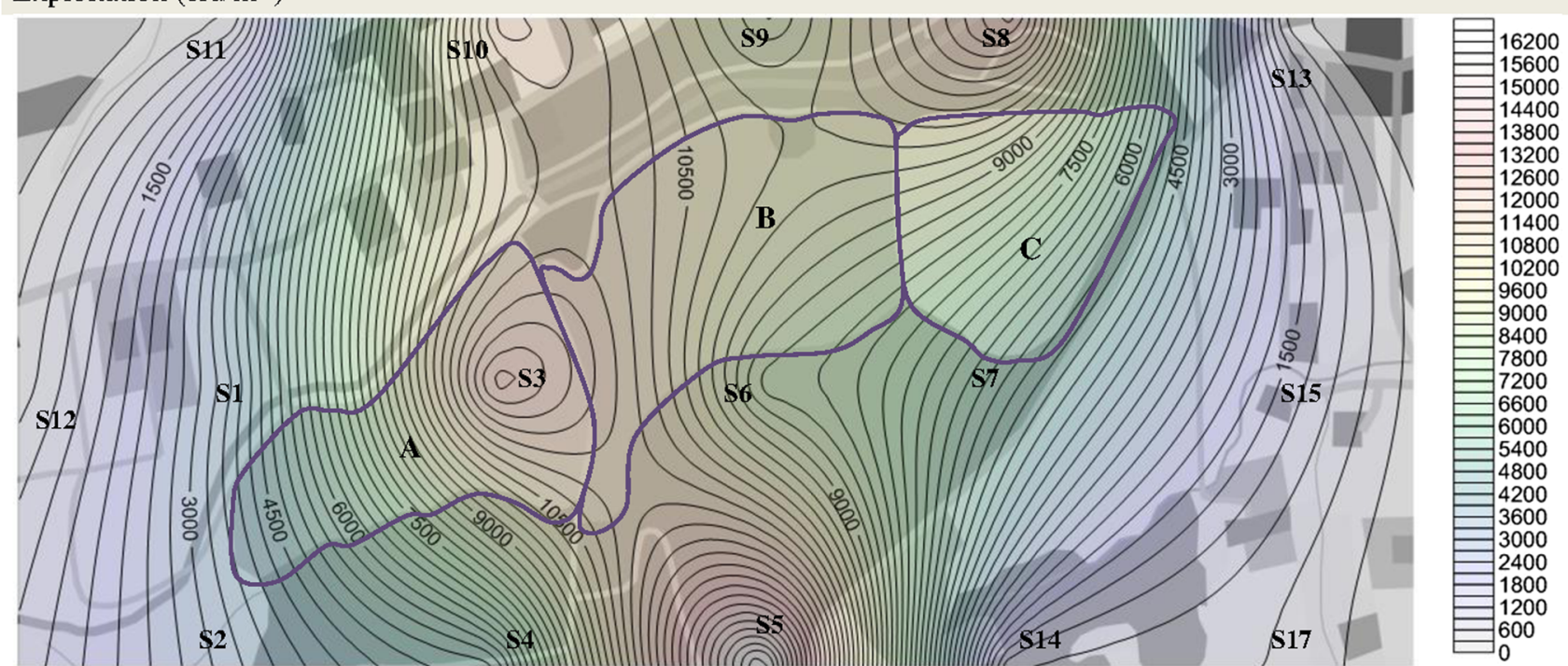

\section{B}

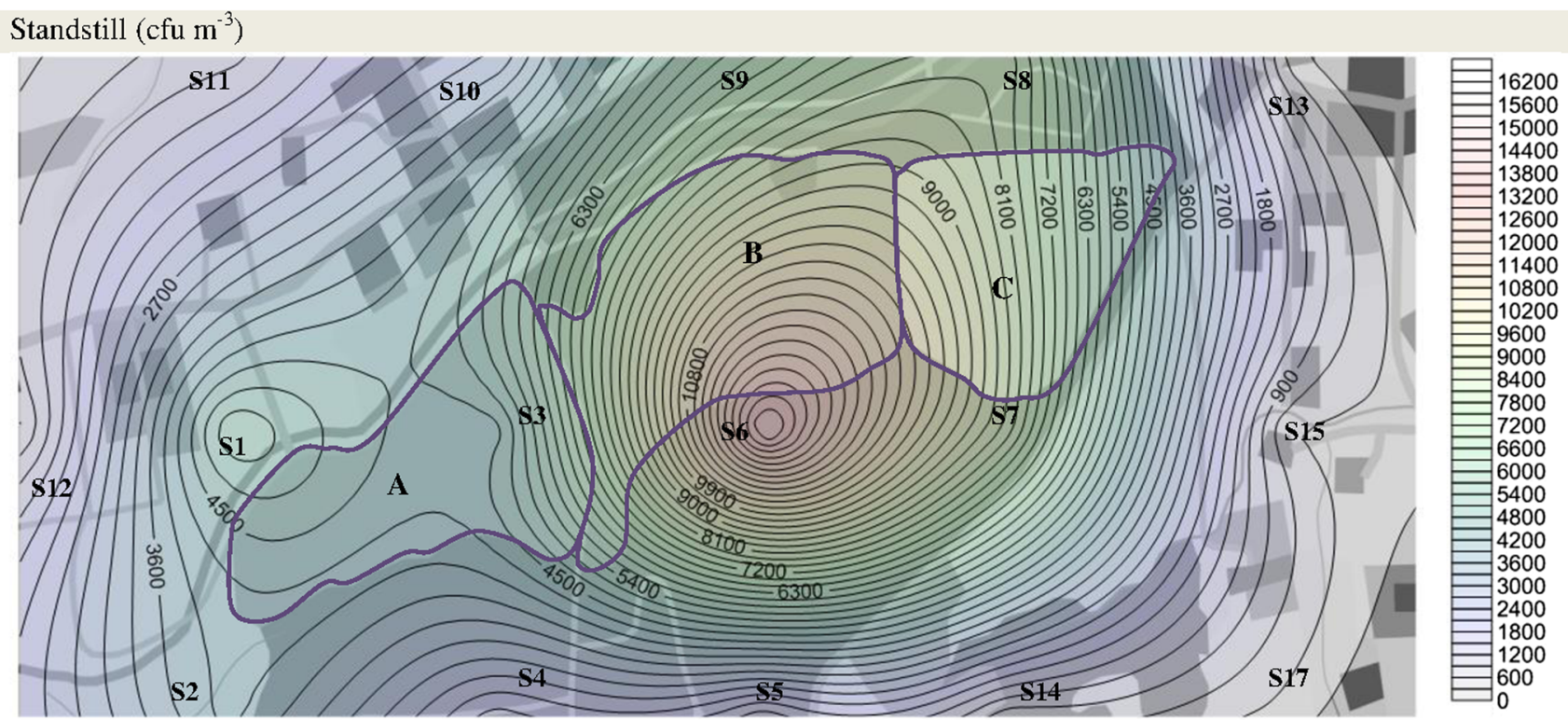

Fig. 2 Distribution of airborne fungi concentration within the municipal landfill area during the exploitation and standstill periods. The map is the result of the imposition of the isopleth map on the background of the landfill area plan implemented as a graphic to one of the map layers. A Active sector, currently exploited; $B$ and
$C$ inactive, closed and recultivated sectors. The sites from $\mathrm{S} 4$ to $\mathrm{S} 9$ were located within the forest zone. The sites S1, S10, S12, S13, S15$\mathrm{S} 17$ were located in farmlands. The sites S2, S11, S14 refer to corresponding meadows

season. At the time of exploitation, higher concentrations of fungi were ascertained in the active sector (S3) and within its close surroundings. These results are reported in the form of graphical maps, illustrating the distribution of fungal cfu within the landfill area (Fig. 2). The standstill period on the landfill resulted in reduction in fungal presence in the air samples. However, these concentrations mechanical equipment as well as their covering lead to the increase in the dust pollution and by that to augmentation of microbial load in the air (Fraczek and Ropek 2011). In this study, the concentrations of fungi were also determined with respect to the landfill exploitation or standstill conditions. These data were gathered in summer only, since the fungal concentrations were distinctly higher during that 

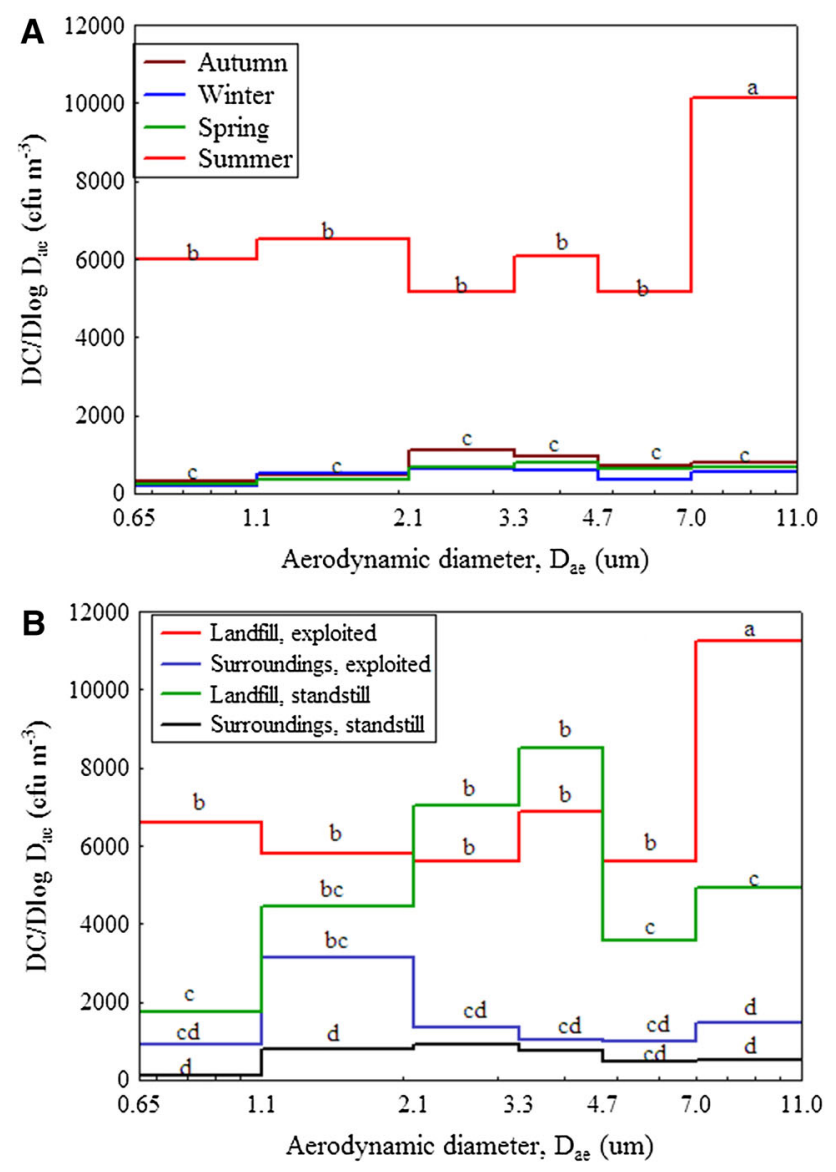

Fig. 3 Particle size distribution of the fungal aerosol in the landfill area: A seasonal changes and $\mathbf{B}$ working status of the landfill. For each size range, significant differences $(p \leq 0.01)$ between means are indicated by different letters

were still higher in several sites compared to those found in the areas located at longer distances beyond the studied landfill.

Considering the distribution of particle sizes, most of the fungal and dust aggregates were included in the fraction above $7 \mu \mathrm{m}$ in summer (Fig. 3a). For this season, increased concentrations of particle sizes within the fraction of 3.3-4.7 $\mu \mathrm{m}$ (e.g. single coarse conidia of Penicillium, Alternaria and Fusarium, as well as small fungal or fungaldust aggregates), and those within the fraction of 1.1-2.1 $\mu \mathrm{m}$ (e.g. single fine conidia mainly Cladosporium and Aspergillus) were observed. However, almost solely single conidia were released during other seasons. during the landfill exploitation. Higher RH found in these seasons supported the increased fungal growth and formation of more compact colonies, resulting in lower emission of their propagules to the air. In turn, lower RH in summer was an environmental stress to fungi inducing higher production of spores. Consequently, higher emission of spores and conidia to the air was ascertained in these unfavourable conditions.

Considering the landfill activity status, significantly high (LSD test; $p \leq 0.01$ ) abundances of the fungal and dust aggregates were found in the fraction above $7 \mu \mathrm{m}$ during the exploitation period (Fig. 3b). In contrast, smaller fungal propagules (i.e. single conidia and small aggregates from the fraction of 2.1-4.7 $\mu \mathrm{m}$ ) were mostly emitted (LSD test; $p \leq 0.01)$ to the air during the standstill term of the landfill. For the surroundings, only fine conidia (the fraction below $2.1 \mu \mathrm{m}$ ) were relatively higher represented during the exploitation period. This could be related to their transportation beyond the landfill because of fine conidia remained airborne for a longer period of time. Conversely, mostly uniform distribution of particle sizes was observed in the landfill surroundings at the standstill term. As a result, the air was less contaminated with single spores or small fungal-dust aggregates, and the area became more environmental safe during this period.

These results indicate that the landfill workers can be exposed to hazardous contents of fungi regardless of the level of activity in the active sector. The bioaerosol particles (i.e. conidia, small and large fungal aggregates and/or dust-borne fungi) are risky for man because of deeper penetration into the respiratory system resulting in some allergic inflammation or other pulmonary diseases (Douwes et al. 2003; Denning et al. 2014). In turn, even the presence in the surrounding area may be associated with inhalation of the bioaerosol during the landfill exploitation time. For this case, the threat is related to the fraction of diameter below $2.5 \mu \mathrm{m}$ that is considered as "Risk Groups" according to the DIN ISO7708 (Clauß 2015). These fine particles, if present, may induce allergic alveolitis after inhalation by exposed people. However, this threat diminishes during the standstill term because single spores from degrading organic matter or small aggregates of fungi, and dust are then emitted into the air. As a result, the transportation of these particles from the landfill to the surroundings is reduced.

\section{Qualitative analysis of fungal aerosol}

In this study, 65 species of airborne fungi were identified within the landfill area during its exploitation phase, whereas this number decreased to 52 species during the standstill period. The analysis using two-way Venn method indicated that 43 species were shared during both landfill activity periods, whereas 22 and nine species were characteristic for the exploitation and standstill phase, respectively. Thus, for example, within the active sector (S3), during the landfill exploitation, Botrytis cinerea (17.5\%), 
Table 1 Contribution of airborne fungal species (unique or shared) in the landfill area depending on its activity status (exploited vs. standstill) as assessed by a two-way Venn analysis

\begin{tabular}{lrrll}
\hline Site & Exploitation & \multicolumn{1}{l}{ Standstill } & Shared & Shared species \\
\hline 1 & $6(33.3 \%)$ & $9(50.0 \%)$ & $3(16.7 \%)$ & Clsph, Clclad, Chaetsp \\
2 & $6(33.3 \%)$ & $10(55.6 \%)$ & $2(11.1 \%)$ & Clsph, Clclad \\
3 & $5(27.8 \%)$ & $7(38.9 \%)$ & $6(33.3 \%)$ & Clclad, Clherb, Aspfl, Aspfum, Aspsp, Chryssp \\
4 & $9(47.4 \%)$ & $6(31.6 \%)$ & $4(21.1 \%)$ & Fussp, Clclad, Clsp, Clsph \\
5 & $10(52.6 \%)$ & $6(31.6 \%)$ & $3(15.8 \%)$ & Clsph, Clclad, Aspclav \\
6 & $6(42.9 \%)$ & $5(35.7 \%)$ & $3(21.4 \%)$ & Clclad, Fusox, Fussam \\
7 & $10(58.8 \%)$ & $4(23.5 \%)$ & $3(17.6 \%)$ & Clclad, Altsp, Clherb \\
8 & $11(55.0 \%)$ & $4(20.0 \%)$ & $5(25.0 \%)$ & Clclad, Fuscro, Penau, Acrce, Altal \\
9 & $16(66.7 \%)$ & $6(25.0 \%)$ & $2(8.3 \%)$ & Clclad, Aspus \\
10 & $5(35.7 \%)$ & $7(50.0 \%)$ & $2(14.3 \%)$ & Clsph, Clclad \\
11 & $5(35.7 \%)$ & $5(35.7 \%)$ & $4(28.6 \%)$ & Pencit, Clclad, Clherb, Clsp \\
12 & $7(46.7 \%)$ & $5(33.3 \%)$ & $3(20.0 \%)$ & Sporsp, Aspsp, Oidgris \\
13 & $5(45.5 \%)$ & $6(54.6 \%)$ & 0 & \\
14 & $6(42.9 \%)$ & $6(42.9 \%)$ & $2(14.3 \%)$ & Aspnig, Sporsp \\
15 & $9(50.0 \%)$ & $6(33.3 \%)$ & $3(16.7 \%)$ & Aspfum, Chrysp, Penchry \\
16 & $7(41.2 \%)$ & $7(41.2 \%)$ & $3(17.6 \%)$ & Aspnig, Geosp, Acrsp \\
17 & $8(57.1 \%)$ & $2(14.3 \%)$ & $4(28.6 \%)$ & Acrsp, Rhomin, Clclad, Penspin \\
\hline
\end{tabular}

a Acrsp Acremonium sp., Acrce A. cerealis, Altsp Alternaria sp., Altal A. alternata, Aspsp Aspergillus sp., Aspfl A. flavus, Aspfum A. fumigatus, Aspus A. ustus, Aspnig A. niger, Aspclav A. clavatus, Chaetsp Chaetomium sp., Clsp Cladosporium sp., Clsph Cl. sphaerospermum, Cclad Cl. cladosporioides, Clherb Cl. herbarum, Chryssp Chrysosporium sp., Chrysp Chrysonilia sp., Fussp Fusarium sp., Fusox F. oxysporum, Fussam $F$. sambucinum, Fuscro $F$. crookwellense, Geosp Geotrichum sp., Oidgris Oidiodendron griseum, Penau Penicillium aurantiogriseum, Pencit $P$. citrinum, Penchry $P$. chrysogenum, Penspin $P$. spinulosum, Rhomin Rhodotorula minuta, Sporsp Sporotrichum sp
C. cladosporioides (13.5\%) and A. fumigatus (5.7\%) predominated in bioaerosol samples, whereas Fusarium equiseti (11.5\%), C. cladosporioides (11.2\%) and Acremonium butyri $(9.9 \%)$ prevailed in the air during the standstill phase. At other sampling sites, different species were identified in the bioaerosol. They mostly belonged to genera: Aspergillus, Cladosporium, Penicillium, Alternaria, Acremonium, Trichoderma, Mucor and Fusarium. Also the yeast strains, representing either Candida, Geotrichum or Rhodotorula genera, were found at a few landfill sites (i.e. S4, S5, S6, S13, S14 and S17). Their occurrence confirmed earlier observations by Lis et al. (2004) perceived at active landfill areas in Upper Silesia and the Sandomierz Basin. Considering the fungal community composition within respective sites, a distinct predomination of species unique to the exploitation or standstill period was found (Table 1). However, a higher contribution of species that were detected in both terms was mostly observed in the site S3. A relatively high amount of the same airborne isolates was still detected in the active sector (S3, 33.3\%) and adjacent forest sites (S4 and S8, 21-25\%) in the standstill period. For other sites, except the sites S11 (28.6\%) and S17 (28.6\%), the communities shared lower number of species (0-21\%) during this period compared to those of the exploited landfill. In addition, the number of species significantly decreased in the sites S9 and S17 at the standstill period. These results suggest that distinct shift in the species composition may occur when the activity within the active sector is suspended.

Abdel Hameed et al. (2015) found representatives of 23 genera among fungal isolates in the air of landfill with distinct prevalence of A. fumigatus, A. flavus as well as Penicillium and Cladosporium species. Huang et al. (2002) classifying airborne fungi in municipal landfill sites supplemented that list with Drechslera and Alternaria strains. Also, Buczyńska et al. (2006) studying municipal waste landfills detected only six species; however, A. fumigatus and $A$. niger were still the most abundant ones.

The presence of different microscopic fungi in the air of landfills and their surroundings results in significant changes in the environmental quality of these areas (Douwes et al. 2003; Abdel Hameed et al. 2015; Schlosser et al. 2016). Hence, identification of fungal taxa in air samples collected from these sites is important as individual species, differing in aerodynamic diameters, may cause various adverse health effects in exposed people (De Hoog et al. 2000; Yamamoto et al. 2012).

To the best of our knowledge, the species composition of airborne fungi during the landfill exploitation and standstill periods has not been so far compared. As might 
be expected, some fungal species occurred in the air during the exploitation phase only, originating probably from fresh wastes delivered to the landfill and/or from already collected wastes. More problematic is explanation of the presence of the species characteristic for the time of no activity at the landfill. These species (i.e. Emericella nidulans, Ulocladium chartarum, Aspergillus ochraceus, $A$. sydowii, Fusarium graminearum, Rhodotorula mucilaginosa, Trichoderma sp., Geotrichum capitatum and Mucor racemosus) were only found in the sites located in the area surrounding the studied landfill, mostly farmland (S12S16) and forest (S7, S9). It may be presumed that their source was not related to waste and was rather connected with different type of degraded organic matter and residues or plant surfaces in agricultural and forest locations. For example, vegetation has been suggested as a significant source of air contamination with Ulocladium, Alternaria or Fusarium (Fenn et al. 1989; Awad 2005; Fang et al. 2008).
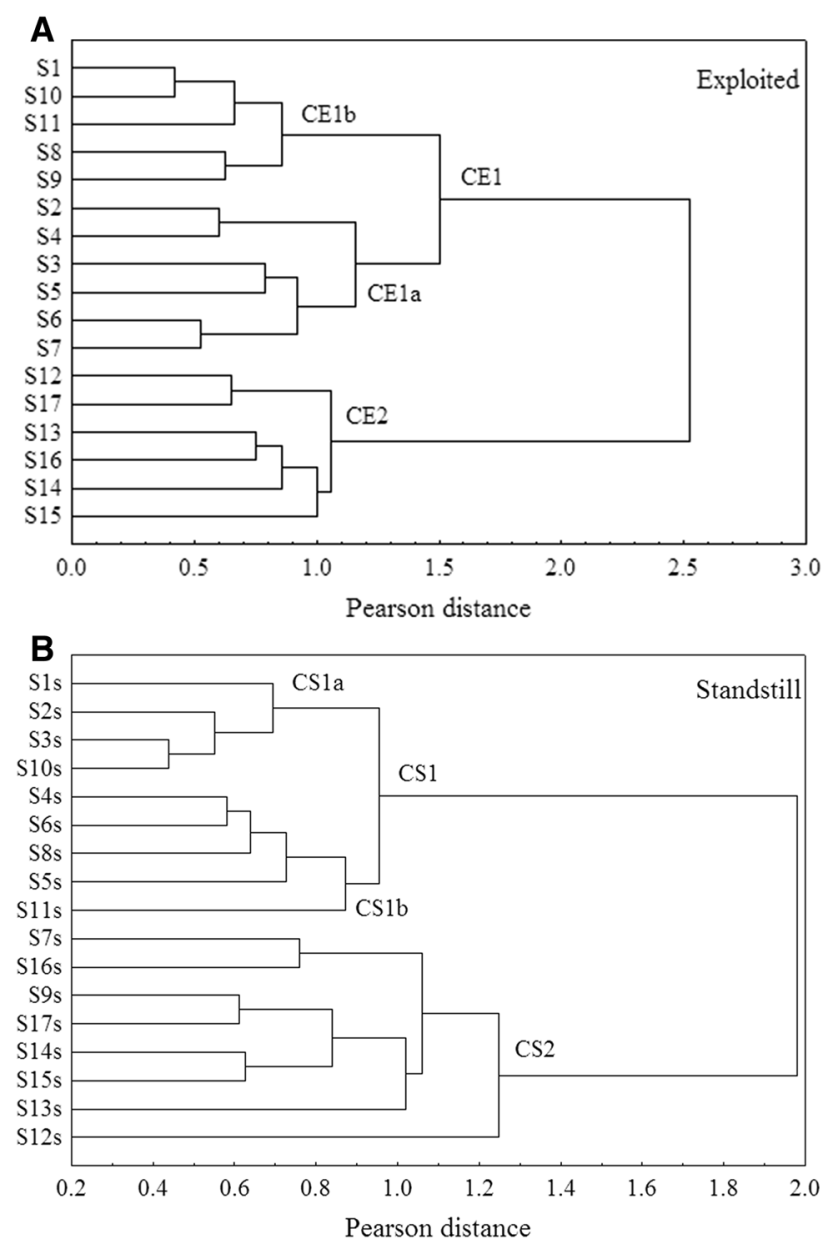

Fig. 4 Dendrograms representing similarities in the qualitative composition of airborne mycobiota at different sites (S1-S17) of the landfill area during exploitation and standstill periods
On the above described observations certain influence may also have the distance from the landfill (Kaarakainen et al. 2008; Kaźmierczuk and Bojanowicz-Bablok 2014; Schlosser et al. 2016). In this study, the species pattern analysis covering all sampling sites during the landfill exploitation showed two major clusters grouping these places according to the distance from the active site (S3) (Fig. 4). For the cluster CE1, further two sub-clusters were differentiated depending on the localization towards the site S3. The species composition for south oriented sites (CE1a) indicated higher similarity to that of S3 compared to the sites localized in the north (CE1b). The sub-cluster CE1b grouping the forest sites (S8, S9) and agricultural sites (S1, S10, S11) suggests a higher local impact on the specific composition of fungal community. For the cluster CE2, the sites distantly localized towards the landfill were differentiated, indicating separate species patterns characteristic for the surrounding area.

For the standstill phase, the cluster analysis also indicated two composite clusters (i.e. CS1, CS2), showing similar grouping principle as for the exploitation period (Fig. 4). However, different relationships between respective sites within the clusters were found. The species pattern in the active site (S3) showed closer similarity to the adjacent agricultural sites (S1, S2, S10), forming the subcluster CS1a. In contrast, the second sub-cluster CS1b composed mostly the forest sites. The species patterns, representing the sites located at longer distance from the S3, were grouped into the cluster CS2. For this cluster also included the patterns of forest sites S7 and S9, which were found in the CE1 cluster, for the exploited time.

The results of cluster analysis showed that the fungal community in the bioaerosol of landfill area changes depending on the activity of a specific site and is influenced by the other localized emission sources. Agricultural or forest sites in the surrounding area, especially those located at a considerable distance from the landfill, having higher local specificity revealed genuine fungal communities and lower dependence on the impact of the landfill on the composition of fungal species in the air.

\section{Cytotoxicity of A. fumigatus strains}

In this study, 21 different strains of A. fumigatus were isolated from the landfill area. All of them indicated cytotoxic activity expressed at various levels, depending on the fungal extract concentrations used in the MTT assay (Table 2). Six strains showed low cytotoxicity $\left(\mathrm{IC}_{50} \geq 7.813\right.$ to $\leq 15.625 \mathrm{~cm}^{2} \mathrm{~mL}^{-1}$ ), whereas remaining 15 isolates caused damages of the SK cells at moderate intensity with $\mathrm{IC}_{50}$ between 0.488 and $3.906 \mathrm{~cm}^{2} \mathrm{~mL}^{-1}$. None of the strains was recognized as highly toxic $\left(\mathrm{IC}_{50} \leq 0.244 \mathrm{~cm}^{2} \mathrm{~mL}^{-1}\right)$. 
Table 2 Cytotoxicity of $A$. fumigatus strains isolated from different sites of the landfill

\begin{tabular}{|c|c|c|c|c|c|}
\hline Strain & Site & $\mathrm{IC}_{50}\left(\mathrm{~cm}^{2} \mathrm{~mL}^{-1}\right)$ & Toxicity level & Dilution $^{\mathrm{a}}$ & Concentration $^{\mathrm{a}}\left(\mathrm{cm}^{2} \mathrm{~mL}^{-1}\right) /$ toxicity \\
\hline AM8 & $\mathrm{S} 3$ & 3.906 & ++ & 1 & $31.250 /+$ \\
\hline AM9 & $\mathrm{S} 3$ & 3.906 & ++ & 2 & $15.625 /+$ \\
\hline AM10 & $\mathrm{S} 1$ & 15.625 & + & 3 & $7.813 /+$ \\
\hline AM11 & $\mathrm{S} 2$ & 7.813 & + & 4 & $3.906 /++$ \\
\hline AM12 & $\mathrm{S} 3$ & 3.906 & ++ & 5 & $1.953 /++$ \\
\hline AM27 & $\mathrm{S} 4$ & 3.906 & ++ & 6 & $0.977 /++$ \\
\hline AM28 & S6 & 1.953 & ++ & 7 & $0.488 /++$ \\
\hline AM29 & S7 & 0.488 & ++ & 8 & $0.244 /+++$ \\
\hline AM30 & $\mathrm{S} 3$ & 3.906 & ++ & 9 & $0.122 /+++$ \\
\hline AM31 & S9 & 0.977 & ++ & 10 & $0.061 /+++$ \\
\hline AM32 & $\mathrm{S} 10$ & 1.953 & ++ & & \\
\hline AM33 & S10 & 0.977 & ++ & & \\
\hline AM34 & $\mathrm{S} 10$ & 0.977 & ++ & & \\
\hline AM35 & S5 & 15.625 & + & & \\
\hline AM38 & S16 & 1.953 & ++ & & \\
\hline AM39 & S11 & 15.625 & + & & \\
\hline AM41 & $\mathrm{S} 12$ & 7.813 & + & & \\
\hline AM42 & S14 & 3.906 & ++ & & \\
\hline AM43 & $\mathrm{S} 17$ & 1.953 & ++ & & \\
\hline AM44 & S16 & 3.906 & ++ & & \\
\hline AM51 & $\mathrm{S} 13$ & 15.625 & + & & \\
\hline
\end{tabular}

a Successive dilutions and corresponding concentrations of fungal extracts used in the MTT test. The concentrations were expressed in $\left(\mathrm{cm}^{2} \mathrm{~mL}^{-1}\right)$ of Petri plate surface from which the mould was collected for the extraction. Symbols,,++++++ levels of toxicity; low, moderate and high levels of toxicity, respectively
For the active sector (S3), all four isolated strains indicated moderate cytotoxicity. However, only six out of 17 strains isolated from the surrounding areas were considered as cytotoxic at the low concentrations. For example, the strains obtained from the forest zone (i.e. AM28 and AM29) showed similar moderate toxicity as the strain (i.e. AM30) isolated from the active sector (Fig. 5). In turn, both low and intermediate cytotoxic strains were found at the sites located far away from the active sector, i.e. S13 and S16, respectively (Fig. 5). Furthermore, low cytotoxic strains were isolated from the farmland (S1, S12), meadow (S2, S11, S13) and forest zone (S5) sites (Table 1). These sampling points were almost solely located on the leeward side of the landfill.

Aspergillus fumigatus has frequently been found in the bioaerosol samples in municipal landfills (Krikštaponis et al. 2001; Kaarakainen et al. 2008; Kalwasińska et al. 2014; Schlosser et al. 2016). For air quality assessment, identification of $A$. fumigatus strains capable to produce mycotoxins is of great importance. These secondary metabolites are present in both viable and non-viable spores or other fungal propagules. Numerous cytotoxic properties have been associated with mycotoxins (Hedayati et al. 2007; Gauthier et al. 2012; Aiko and Mehta 2015). In addition, organic dust may be contaminated with the fungal metabolites (Fischer et al. 1999, 2000; Despot et al. 2016).

Fungi are cytotoxic under specific environmental conditions enabling them to produce mycotoxins, for example, availability of nutrients or presence of other moulds (Kelman et al. 2004; Despot et al. 2016). Variability of environmental factors such as moisture, temperature, water activity, the presence of nitrogen or good oxygenation may lead to activation of genes responsible for production of a specific toxin, e.g. gliotoxin by A. fumigatus (Watanabe et al. 2004; Singh and Del Poeta 2011). Gniadek et al. (2011) found that almost all strains of A. fumigatus isolated from indoor air of adult intensive care unit in a hospital were either moderate or highly cytotoxic. Sterigmatocystin-producing Aspergilli, cytotoxic to human lung cells, were also detected in air samples from living and occupational (i.e. grain mill) sites by Despot et al. (2016). Gauthier et al. (2012) reported that A. fumigatus conidia were able to produce five different toxins, but only 


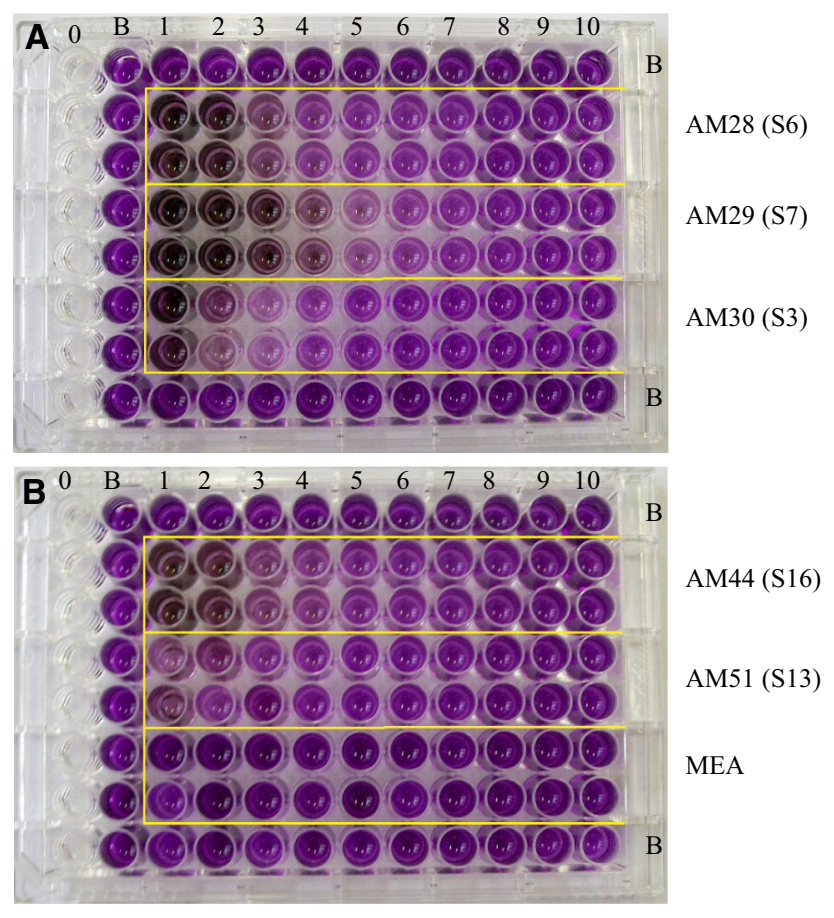

Fig. 5 MTT assay results of airborne A fumigatus strains isolated from the corresponding sites of the landfill (in parentheses). 1 to 10successive dilutions of the fungal extracts, corresponding to the tested concentrations from 31.25 to $0.061 \mathrm{~cm}^{2} \mathrm{~mL}^{-1}$. 0-control samples for a microplate reader; $\mathbf{B}$ protective cell barrier; MEA-noninoculated growth medium (test control samples)

trypacidin was highly toxic to lung cells. Fischer et al. (1999) also reported that several strains of A. fumigatus isolated from the air at compost facility were capable to produce a wide range of these harmful secondary metabolites.

In this study, we found for the first time that cytotoxic strains of A. fumigatus may also be detected in the bioaerosol sampled within the municipal landfill and in its close vicinity. However, the performed analysis revealed the lack of highly toxic strains at the active sector and beyond the studied landfill (including the neighbouring area) that is positive information to the landfill workers and residents from both health and environmental points of view.

\section{Conclusion}

The obtained results confirmed the assumption that fungal aerosol differ on both quantitatively and qualitatively in respective sites of the landfill and surrounding area. Within the landfill area, particular sites may be grouped with regard to airborne fungi concentrations and similarity in species composition. Different particle sizes of the bioaerosol are found within the landfill and surroundings depending on the works performed in the active sector. In consequence, an increased exposition to the hazardous particles above $7 \mu \mathrm{m}$ occurs in the landfill during the exploitation period. However, smaller fungal propagules (e.g. single conidia and small aggregates) prevail when the active works are suspended. In the surrounding areas, relatively low uniform distribution of different fungal particles during both period results in increased safety compared to the landfill sites. The exposition to the bioaerosol particles is significantly higher in summer when atmospheric conditions are more suitable for airborne fungi. Higher air humidity at other seasons supports the increased fungal growth and formation of more compact colonies, resulting in lower emission of their propagules to the air. In addition, the exposition may also be associated with an inhalation of cytotoxic strains of A. fumigatus, especially in the active sector, where more efficient producers of mycotoxins are ascertained. Further studies are needed to evaluate a correlation between the presence of toxic fungal strains and range of mycotoxin concentrations, thus a threat level, in respective sites within the landfill area. Furthermore, it is also important to be aware of the distribution of different fungal species depending on the exploitation or standstill period of the landfill. Although most species are common during these periods, the landfill workers and visitors in the surroundings can be exposed to distinct species during both times. In consequence, microbial monitoring of the landfill and surrounding area should be carried out taking into account both quantitative aspect supplemented by size distribution analysis and qualitative features, especially of those strains possessing cytotoxic activity. 
Acknowledgements This study was financially supported by the National Science Centre, Poland (N N304 308549).

Open Access This article is distributed under the terms of the Creative Commons Attribution 4.0 International License (http:// creativecommons.org/licenses/by/4.0/), which permits unrestricted use, distribution, and reproduction in any medium, provided you give appropriate credit to the original author(s) and the source, provide a link to the Creative Commons license, and indicate if changes were made.

\section{References}

Abdel Hameed AA, Habeebuallah T, Mashat B, Elgendy S, Elmorsy TH, Elserougy S (2015) Airborne fungal pollution at waste application facilities. Aerobiologia 31:283-293

Aiko V, Mehta A (2015) Occurrence, detection and detoxification of mycotoxins. J Biosci 40:943-954

Awad AHA (2005) Vegetation: a source of air fungal bio-contaminant. Aerobiologia 21:53-61

Buczyńska A, Cyprowski M, Szadkowska-Stańczyk I (2006) Biological hazards in air at municipal waste landfills. Med Pracy 57:531-535

De Hoog GS, Guarro J, Gene G, Figueiras M (2000) Atlas of clinical fungi, 2nd edn. Centraalbureau voor Schimmelcultures, Utrecht

Denning DW, Pashley C, Hartl D, Wardlaw A, Godet C, Del Giacco S, Delhaes L, Sergejeva S (2014) Fungal allergy in asthma: state of the art and research needs. Clin Transl Allergy 4:14

Despot DJ, Kocsubé S, Bencsik O, Kecskeméti A, Szekeres A, Vágvölgyi C, Varga J, Klarić MS (2016) Species diversity and cytotoxic potency of airborne sterigmatocystin-producing Aspergilli from the section Versicolores. Sci Total Environ 562:296-304

Douwes J, Thorne P, Pearce N, Heederik D (2003) Bioaerosol health effects and exposure assessment: progress and prospects. Ann Occup Hyg 47:187-200

Fang Z, Ouyang Z, Zheng H, Wang X (2008) Concentration and size distribution of culturable airborne microorganisms in outdoor environments in Beijing, China. Aerosol Sci Technol 42:325-334

Fenn ME, Dunn PH, Durall DM (1989) Effects of ozone and sulfur dioxide on phyllosphere fungi from three tree species. Appl Environ Microbiol 55:412-418

Fischer G, Müller T, Ostrowski R, Dott W (1999) Mycotoxins of Aspergillus fumigatus in pure culture and in native bioaerosols from compost facilities. Chemosphere 38:1745-1755

Fischer G, Müller T, Schwalbe R, Ostrowski R, Dott W (2000) Exposure to airborne fungi, MVOC and mycotoxins in biowastehandling facilities. Int J Hyg Health 203:97-104

Fisher F, Cook NB (1998) Fundamentals of diagnostic mycology. W.B. Saunders, Philadelphia

Frączek K, Kozdrój J (2016) Strain differentiation of airborne opportunistic microorganisms within a municipal landfill area as assessed by PCR MP method. Aerobiologia 32:499-511

Fraczek K, Ropek D (2011) Municipal waste dumps as the microbiological threat to the natural environment. Ecol Chem Eng S 18:93-110

Gauthier T, Wang X, Dos Santos JS, Fysikopulos A, Tadrist S, Canlet C, Artigot MP, Loiseau N, Oswald IP, Puel O (2012) Trypacidin, a spore-borne toxin from Aspergillus fumigatus, is cytotoxic to lung cells. PLoS ONE 7:e29906
Gniadek A, Macura AB, Twarużek M, Grajewski J (2010) Cytotoxicity of Aspergillus strains isolated from the neonatal intensive care unit environment. Adv Med Sci 55:242-249

Gniadek A, Macura AB, Górkiewicz M (2011) Cytotoxicity of Aspergillus fungi isolated from hospital environment. Pol J Microbiol 60:59-63

Górny RL, Cyprowski M, Ławniczek-Wałczyk A, Gołofit-Szymczak M, Zapór L (2011) Biohazards in the indoor environment: a role for threshold limit values in exposure assessment. In: Management of indoor air quality. Leiden: CRC Press/Balkema, pp 1-20

Grisoli P, Rodolfi M, Villani S, Grignan E, Cottica D, Berri A, Picco AM, Dacarro C (2009) Assessment of airborne microorganism contamination in an industrial area characterized by an open composting facility and a wastewater treatment plant. Environ Res 109:135-142

Hanelt M, Gareis M, Kollarczik B (1994) Cytotoxicity of mycotoxins evaluated by the MTT-cell culture assay. Mycopathologia 128(3): 167-174

Hedayati MT, Pasqualotto AC, Wam PA, Bowyer P, Denning DW (2007) Aspergillus fumigatus: human pathogen, allergen and mycotoxin producer. Microbiology 153:1677-1692

Huang CY, Lee CC, Li FC, Ma YP, Jenny Su HJ (2002) The seasonal distribution of bioaerosols in municipal landfill sites: a 3-year study. Atmos Environ 36:4385-4395

Kaarakainen P, Meklin T, Rintala H, Hyvärinen A, Kärkkäinen P, Vepsäläinen A, Hirvonen MR, Nevalainen A (2008) Seasonal variation in airborne microbial concentrations and diversity at landfill, urban and rural sites. Clean 36:556-563

Kalwasińska A, Burkowska A, Swiontek Brzezinska M (2014) Exposure of workers of municipal landfill site to bacterial and fungal aerosol. Clean 42:1337-1343

Kaźmierczuk M, Bojanowicz-Bablok A (2014) Bioaerosol concentration in the air surrounding municipal solid waste landfill. Environ Prot Nat Resour 25(2):17-25

Kelman B, Robbins C, Swenson L, Hardin B (2004) Risk from inhaled mycotoxins in indoor office and residential environments. Int J Toxicol 23:3-10

Krikštaponis A, Lugauskas A, Krysińska-Traczyk W, Prażmo Z, Dutkiewicz J (2001) Enzymatic activities of Aspergillus fumigatus strains isolated from the air at waste landfills. Ann Agric Environ Med 8:227-234

Lanier C, Richard E, Heutte N, Picquet R, Bouchart V, Garon D (2010) Airborne molds and mycotoxins associated with handling of corn silage and oilseed cakes in agricultural environment. Atmos Environ 44:1980-1986

Lis D, Ulfig K, Wlazło A, Pastuszka JS (2004) Microbial air quality in offices at municipal landfills. J Occup Environ Hyg 1:62-68

Menzies D, Holmes L, McCumesky G, Prys-Picard C, Niven R (2011) Aspergillus sensitization is associated with airflow limitation and bronchiectasis in severe asthma. Allergy 66:679-685

Nielsen BH, Nielsen EM, Breum NO (2000) Seasonal variation in bioaerosol exposure during biowaste collection and measurements of leaked percolate. Waste Manag Res 18:64-72

Samson RA, Hoekstra ES, Frisvad JC, Fitenborg O (2004) Introduction to food- and airborne fungi, 7th edn. Centraalbureau voor Schimmelcultures, Utrecht

Schlosser O, Robert S, Debeaupuis C (2016) Aspergillus fumigatus and mesophilic moulds in air in the surrounding environment downwind of non-hazardous waste landfill sites. Int J Hyg Environ Health 219:239-251

Singh A, Del Poeta M (2011) Lipid signalling in pathogenic fungi. Cell Microbiol 13:177-185

Sudini H, Srilakshmi P, Krishna Kumar KV, Nioroge SMC, Osiru M, Seetha A, Waliyar F (2015) Detection of aflatoxigenic 
Aspergillus strains by cultural and molecular methods: a critical review. Afr J Microbiol Res 9:484-491

Watanabe A, Kamei K, Sekine T, Higurashi H, Ochiai E, Hashimoto Y, Nishimura K (2004) Cytotoxic substances from Aspergillus fumigatus in oxygenated or poorly oxygenated environment. Mycopathologia 158:1-7
Yamamoto N, Bibby K, Qian J, Hospodsky D, Rismani-Yazdi H, Nazaroff WW, Peccia J (2012) Particle-size distributions and seasonal diversity of allergenic and pathogenic fungi in outdoor air. ISME J 6:1801-1811 